\title{
"O passado é uma roupa que não nos serve mais": a política habitacional entre avanços-e-retrocessos
}

"The past is clothing that no longer fits housing": policies between progress and regress

\author{
Manoela Rodrigues Munhoz* \\ Cassia Pilar Salgado** \\ Jade Graziele Martins dos Santos***
}

\begin{abstract}
Resumo:
O presente artigo aborda a questão habitacional a partir das discussões sobre a apropriação do território, o processo de urbanização, o debate sobre o direito à moradia e as formas de mediar os conflitos urbanos por meio da política habitacional brasileira. Busca identificar os avanços na legislação nacional fruto das lutas em torno da reforma urbana e as dificuldades da materialização desses avanços em políticas sociais públicas que alterem o cenário das condições de moradia da classe trabalhadora nas grandes cidades. Por fim, propõe uma reflexão sobre os caminhos trilhados pela política habitacional, hoje centralizadas no Governo Federal mediante o Programa Minha Casa Minha Vida, com vistas a identificar os limites e as conquistas das intervenções públicas na garantia constitucional do direito à moradia digna.
\end{abstract}

Palavras-chave: Território; Urbanização; Questão habitacional; Política habitacional; Programa Minha Casa Minha Vida.

\begin{abstract}
:
This work discusses the housing policies from the point of view of territories appropriation, urbanization processes, and the debate about housing rights and forms to mediate urban conflicts through the brazilian housing policy. The article seeks to identify the advances in national laws as a result of the struggle for urban reforms and the difficulties to materialize this advances with social policies that change workers housing conditions in big cities. Finally, it proposes a reflection on the paths taken by the housing policy, currently centralized by the federal government through the housing program "My House, My Life", aiming to identify governments intervention's limits and achievements in the constitutional guarantee of the right to decent housing.
\end{abstract}

Key-words: Territory; Urbanization; Housing rights; Housing policies; Program My House, My Life.

\section{Introdução}

O presente trabalho busca recuperar a concepção de território para subsidiar o debate sobre o processo de urbanização, questão habitacional, aglomeração e segregação

\footnotetext{
* Assistente Social. Doutoranda do Programa de Pós-Graduação em Serviço Social da PUCRS. E-mail: manoesca@yahoo.com.br

** Assistente Social. Mestranda do Programa de Pós-Graduação em Serviço Social da PUCRS. E-mail: cassiaps91@gmail.com

*** Assistente Social. E-mail: jademartins_@hotmail.com
} 
social, temas considerados pertinentes para a reflexão dos mecanismos e dos caminhos adotados pela política habitacional brasileira. O título faz alusão à música "Velha Roupa Colorida" do compositor Belchior, como forma a ilustrar a necessidade de rupturas e de superações no âmbito das estratégias de enfrentamento da questão habitacional no Brasil.

São as relações capitalistas, com base na apropriação parcial das riquezas socialmente produzidas, que demarcam os contornos urbanos dos últimos séculos. As cidades servem de cenário para uma realidade composta por fortes disputas e contradições entre os antagônicos interesses de uma sociedade dividida em classes. Na linha do tempo, diferenciam-se na estrutura organizacional da realidade urbana, momentos de acumulação mercantil, industrial e financeira, como força social de organização do espaço. Nessas distintas etapas, observa-se a insistente manutenção - e agravamento -, da segregação socioespacial, das precárias condições de acesso à moradia da classe trabalhadora e da captura da funcionalidade social do território urbano.

O território é o palco onde são expressas as contradições do modo de produção capitalista. A cidade, por sua característica de aglutinação, reúne os diferentes atores em disputa, deflagrando o confronto entre os interesses do capital e da classe trabalhadora. A produção do espaço urbano é, portanto, permeada por contradições e geradora de tensões entre os distintos segmentos que a constituem. Dessa forma, o território é também espaço da resistência. É o território propriamente dito, acrescido das obras humanas, que revela a forma que o território é usado. Essa é a totalidade, o território, a partir da análise do seu uso, inclui todos os agentes e aspectos, sendo um "todo" onde todos (Estado, empresas, instituições, sujeitos) relacionam-se. O território representa, assim, "o chão do exercício da cidadania, pois cidadania significa vida ativa no território, onde se concretizam as relações sociais, as relações de vizinhança e solidariedade, as relações de poder" (KOGA, 2011, p. 33).

No decorrer dos processos históricos sociais, foram vivenciadas disputas pelo solo urbano. Atualmente, esse contexto é identificado pela luta da sociedade civil organizada na busca da materialização dos avanços constitucionais, via a garantia da prevalência da função social da terra, em detrimento do interesse especulativo imobiliário. No Brasil, cotidianamente são travados embates pelo acesso e permanência nos territórios, sejam rurais, sejam urbanos. Populações indígenas, quilombolas, pessoas em situação de rua, 
sem-teto, sem-terra, são alguns exemplos dos mecanismos de exclusão e da resistência e da luta pela função social da cidade e do acesso à terra.

Como forma de mediar o conflito da disputa de interesses na sociedade dividida em classes, emerge a ação do Estado, expressa substancialmente nas políticas sociais. No bojo da sociedade capitalista, essas políticas são caracterizadas pelo elemento da contradição e, como instrumento de mediação do Estado, podem simultânea e paradoxalmente servir de estímulo para a distribuição ou para a acumulação de riquezas, gerando mobilização ou apatia social. A política social pública de habitação, nesse sentido, insere-se no rol dos instrumentos estatais voltados à mediação do conflito de interesses na apropriação do território urbano. Compreender seus limites e suas possibilidades na construção da cidadania pressupõe desocultar as forças e os interesses que mobilizam a política habitacional, a estrutura e a dinâmica desta no bojo do modo de produção capitalista.

A inserção da pauta sobre a questão habitacional na Constituição Federal de 1988 resulta da luta do movimento social da Reforma Urbana. A carta magna estabelece responsabilidade da provisão de moradia aos três entes federados da nação. A partir da Emenda Constitucional 26/2000, o direito à moradia passa a compor os direitos sociais, reforçando o papel fundamental da União na provisão de moradia para as famílias mais pobres. Ainda fruto da organização do movimento de Reforma Urbana, considera-se importante o avanço no aparato legal promovido pela aprovação do Estatuto da Cidade (BRASIL, 2001), no ano de 2001, este prevê instrumentos de garantia à democratização do direito à cidade, tornando constitucional o direito social à moradia. Como desdobramento do Estatuto e na perspectiva de combate às desigualdades sociais, transformação das cidades em espaços mais humanizados com a ampliação do acesso à moradia, saneamento e transporte, é criado o Ministério das Cidades, no ano de 2003. No ano de 2009, a política habitacional sofre a mais significativa influência das alterações legais, passando a ser centralizada pelo Governo Federal via Programa Minha Casa Minha Vida. Desde então, o programa é responsável por índices históricos de investimento na política habitacional do país. Porém, se quantitativamente o programa representa um marco nessa política, qualitativamente representa um risco de reprodução de experiências (ultra)passadas na área. 


\title{
O território em transformação: o processo de urbanização no Brasil
}

O debate acerca da questão territorial ultrapassa a demarcação de determinado espaço físico, o território é considerado o espaço de sentimentos, de emoções. Ou, ainda,

\begin{abstract}
O território não é apenas o resultado da superposição de um conjunto de sistemas naturais e um conjunto de sistemas de coisas criadas pelo homem. $O$ território é o chão e mais a população, isto é, uma identidade, o fato e o sentimento de pertencer àquilo que nos pertence. $O$ território é a base do trabalho, da residência, das trocas materiais e espirituais e da vida, sobre os quais ele influi (SANTOS, 2001, p. 96).
\end{abstract}

Ao se apropriar do espaço, a sociedade o transforma em território. Dessa forma, o território se constitui no processo de espacialização da sociedade. Por território, entendese, geralmente, a extensão apropriada e usada. A territorialidade humana pressupõe preocupação com o destino, construção do futuro, o território "é um nome político para o espaço de um país" (SANTOS, 2012a, p. 21). É o lugar onde a história do homem plenamente se realiza, a partir das manifestações da sua existência.

A configuração territorial tem sua realidade vinda da materialidade, logo, tem existência material própria, e sua existência social é determinada pelas relações sociais que nela se desenvolvem. Inicialmente, a configuração territorial era tão somente o conjunto dos complexos naturais, à medida que a história avança, essa configuração é dada pelas obras dos homens. Desse modo, a configuração territorial cada vez mais é resultado de uma "produção histórica e tende a uma negação da natureza natural, substituindo-a por uma natureza inteiramente humanizada" (SANTOS, 2012b, p. 62).

Mundialmente, o fenômeno da industrialização foi impulso para o processo de urbanização, reconfigurando as relações estabelecidas nos territórios, sendo responsável pela criação de uma realidade contraditória, na medida em que propiciou, "de um lado, através da produção, a agregação do trabalhador na fábrica e, de outro lado, a concentração social segregadora da moradia no âmbito da residência popular" (SILVA, 1989, p. 17). Nessa contraditória relação de aglomeração e segregação, a cidade se torna palco para a prática da cidadania. Nela produz-se política, realizam-se as atividades econômicas, organiza-se a vida institucional, constituem-se novos sujeitos sociais.

Como resultado do confronto de forças estabelecido entre as distintas classes que ocupam o território urbano, o espaço passa a ser organizado. É o interesse de classe que 
define o arranjo espacial, num processo de seletividade, "arrumado por isso a partir da propriedade privada dos recursos do espaço. E o ordenamento já nasce orientado para a regulação desse estado de coabitação classistamente assimétrico" (MOREIRA, 2011, p. 86). A sociedade burguesa é marcada historicamente pelos conflitos de territorialidade.

Dessa contraditória relação de dependência e rechaço, promovida pelo processo de urbanização industrial, classe dominante e proletariado travam uma disputa pela ocupação do espaço urbano. $O$ acesso à habitação impõe-se como condição para a permanência da população, que passa a migrar massivamente do campo para as cidades. Contudo, a terra urbana na sociedade capitalista é avaliada por seu valor de troca, uma mercadoria, nessa disputa por espaço, quem detém o capital pode eleger o local de moradia de acordo com sua conveniência, empurrando aqueles que não possuem recursos financeiros para a margem, para os espaços sem acesso à infraestrutura urbana, desvalorizados e distantes.

Esses são os determinantes da formação sócio-histórica dos territórios urbanos. É por essa razão que "as condições do local de moradia, ou de sua construção, estão submetidas à mesma dinâmica das relações sociais estabelecidas ao longo da história" (ARAÚJO, 2005, p. 95). Na sociedade capitalista, assim como a terra, a casa se constitui em um bem de consumo, uma mercadoria, identificada por seu valor de troca. Sob essa perspectiva, o acesso à casa é mediado também pelos interesses financeiros, seja pelo mercado imobiliário, seja pela construção civil, seja pela apropriação privada da terra.

\footnotetext{
O porão dos pobres é uma habitação hostil, que a ele resiste como potência estranha, que apenas se lhe entrega na medida mesma em que ele entrega a ela seu suor e sangue, que ele não pode considerar como seu lar - onde ele pudesse finalmente dizer: aqui estou em casa - onde ele se encontra, antes, como estando na casa de um outro, numa casa estranha, que diariamente está à espreita e o expulsa, se não pagar o aluguel. Do mesmo modo ele sabe a qualidade de sua habitação em oposição com a habitação humana residente no outro lado, no céu da riqueza (MARX, 2012, p. 146).
}

A atual conjuntura urbana brasileira tem origem nas relações políticas, econômicas, sociais e culturais estabelecidas no seu singular processo de urbanização iniciado no século XIX. A partir da década de 1930, o modelo agroexportador vai sofrendo as interferências do processo de industrialização, fenômeno responsável pelo tardio, mas intenso, processo de urbanização brasileiro. Altera-se, assim, a relação cidade e campo, com o surgimento 
das fábricas enquanto unidades produtivas e com a modificação da divisão técnica e social do trabalho (SILVA, 1989).

A industrialização tardia refletiu no acelerado e mal planejado processo de urbanização, acarretando problemas de insuficiência de infraestrutura, habitação e disponibilidade de serviços. O processo migratório em direção às cidades brasileiras agravou o cenário de desigualdade social e exclusão territorial. O acesso ao solo urbano mediado pelo dinheiro constitui territórios que se dividem de acordo com as necessidades e as conveniências do mercado. O espaço urbano segregado, a partir das formas de apropriação da terra, expressa as contradições que são a base da sociedade de classe. Em relação ao acesso à moradia, o contingente populacional que chegou às cidades encontrou a apropriação privada do solo urbano como um determinante da questão habitacional.

$\mathrm{Na}$ conformação das cidades, Lojkine (1997) demarca as distintas etapas de organização urbana, identificando que, em sua origem, o pedaço de terra na parte central possuía maior valor do que nas regiões periféricas, haja vista que são nas regiões centrais que os serviços de infraestrutura urbana são inicialmente instalados. Num segundo momento, o autor identifica o crescimento das zonas mais reservadas para o uso das elites, sobretudo com a criação de espaços de distanciamento das camadas populares. No terceiro momento da organização urbana, identifica-se o fenômeno do zoneamento, ou seja, a criação de diferentes zonas voltadas para: escritórios, indústrias, moradia, comércios, por exemplo. Nessa etapa, a região central assume outra função, deixa de ser espaço exclusivo para moradia, tornando-se essencialmente o centro de produção e de consumo.

Essa organização do território é orquestrada para adequá-lo aos interesses do capital. Os espaços vão se consolidando e legitimando a partir de um discurso hegemônico, no qual adaptar a cidade a esses interesses recebe tratamento de inevitabilidade e da naturalização dos processos de exclusão. Contudo, esse fenômeno não se dá sem resistência, pois, assim como apontado por Marx e Engels (2001), o cenário de segregação e situação limítrofe de subsistência da classe trabalhadora - e daquela privada do trabalho - é também o sinal da impossibilidade do capital se realizar. E, portanto, esse espaço que se modifica de acordo com os interesses do capital é também potencial para a consolidação da resistência popular. A contradição é destruidora, mas também criadora, já que se obriga 
à superação. Desse processo, emergem as forças que se organizam no sentido de reivindicar seu espaço na cidade.

A cidade é a forma reificada dessas relações, mas também do amadurecimento das contradições que lhes são próprias. É a unidade de contrários, não apenas pelas profundas desigualdades, mas pela dinâmica da ordem e da explosão. As contradições, na maioria das vezes, explodem, cotidianamente, invisíveis. Bairros e pessoas pobres, assaltos, lixo, doenças, engarrafamentos, drogas, violência, exploração, mercado de coisas e de corpos transformados em coisas. As contradições surgem como grafites que insistem em pintar de cores e beleza a cidade cinza e feia. Estão lá, pulsando, nas veias que correm sob a pele urbana (IASI, 2013, p. 41)

Dessa forma, ao longo da conformação da cidade capitalista, o que se destaca é uma política urbana voltada para as melhorias da cidade formal/comercial, delineando o contorno da cidade num espaço de segregação socioterritorial. As cidades adaptadas à reestruturação mercantil elaboram projetos urbanísticos para um território estéril, livre da contradição: revitalizado, disciplinado, de paisagens estetizadas. É a cidade fetiche. A segurança na cidade fetiche é garantida pelo Estado, que protege o cidadão-consumidor da outra cidade, a cidade desorganizada, antiestética e perigosa: a cidade informal. As ruas passam a ser espaço privilegiado dos carros, e não do convívio social. Viver na cidade se reduz a produzir e consumir na cidade.

No Brasil, o período que sintetiza as forças de agravamento da questão urbana e suas formas de resistência são as décadas de 1980 e 1990. Vivenciou-se, nesse período, uma forte recessão, a crise econômica associada à chegada do paradigma neoliberal resultou no enxugamento dos investimentos públicos em saneamento e políticas urbanas, refletindo imediatamente no agravamento e na concentração da pobreza. Nas cidades, essa combinação ocasionou o aumento do número de favelas, de ocupações irregulares, de agressões ao meio ambiente e da violência urbana. Contudo, esse mesmo período foi significativo para a politização da questão urbana. O processo de redemocratização da política brasileira proporcionou a confluência de diversas forças, como os movimentos sociais que lutam por moradia, regularização fundiária e políticas públicas, com destaque ao Movimento Nacional pela Reforma Urbana ${ }^{1}$.

\footnotetext{
${ }^{1}$ O Movimento Nacional pela Reforma Urbana define o conceito da reforma urbana como uma nova ética social, que critica a estrutura da cidade como fonte de lucros para poucos em detrimento da pobreza de muitos. Assume-se, portanto, a denúncia do quadro de desigualdade social, considerando a dualidade vivida em uma mesma cidade: a cidade dos ricos e a cidade dos pobres; a cidade legal e a cidade ilegal. Condena a exclusão da maior parte dos habitantes
} 


\section{As formas de enfrentamento da questão habitacional no Brasil}

A moradia é uma necessidade básica da humanidade, a casa se constitui como representação do abrigo, o espaço onde se estabelecem as mais íntimas relações cotidianas, e é, também, o lugar do cuidado, da proteção. Para Bachelard (2000), a casa, por sua funcionalidade - valor de uso -, é ninho e concha. Por outro lado, a moradia expressa pelo conceito da habitação ou unidade habitacional, inserida nos territórios em disputa, engloba outras dimensões, condicionadas predominantemente às relações comerciais, que implicam os limites de uso e ocupação do solo.

A questão habitacional se constitui em um dos principais problemas sociais urbanos no Brasil. O acesso à habitação é uma expressão da questão social ao revelar as formas de ordenamento das relações sociais capitalistas na conformação da sociedade brasileira. Nesse contexto, a habitação é compreendida não apenas por seu valor de uso - como espaço onde se realizam as relações cotidianas necessárias à sobrevivência -, mas essencialmente por seu valor de troca, que a caracteriza como mercadoria, estabelecendo indissociável relação entre a renda e o acesso. "Ao estudar a questão habitacional, entendemos que ela se constitui como parte do complexo e contraditório processo de estruturação urbana da sociedade capitalista" (PINTO, 2005, p. 93). Pode-se dizer que a questão habitacional é a fusão entre a propriedade privada e o capital, configurando uma expressão da seletividade e da segregação social que se ampliam na organização da cidade (MARICATO, 1997).

Como mercadorias caras, a habitação e a infraestrutura urbana não são acessíveis às classes populares. A necessidade de morar, em geral, é suprida pela ocupação de espaços ociosos com a autoconstrução das unidades habitacionais. Assim se conforma a periferia urbana, espaço de residência da classe trabalhadora, constituída por pequenas casas construídas em pequenos lotes, localizadas em vastas áreas, geralmente distantes da zona central e do acesso aos bens e aos serviços das grandes cidades.

O Estado brasileiro, predominantemente liberal até a década de 1930, manteve apenas um tipo de relação com o espaço onde se aglomerava a classe trabalhadora, o território popular, medidas repressivas: via legislação sanitária e ação policial. As condições

da cidade determinada pela lógica da segregação espacial, pela cidade mercadoria, pela mercantilização do solo urbano e da valorização imobiliária, pela apropriação privada dos investimentos públicos em moradia, em transportes públicos, em equipamentos urbanos e em serviços públicos em geral (UZZO; SAULE JUNIOR, 2009). 
de moradia no processo de urbanização brasileiro sempre estiveram condicionadas exclusivamente às regras do mercado. Assim surgem as distintas soluções habitacionais, tanto por seu porte e sua relação fundiária quanto por sua localização territorial.

A necessidade de aglomerar mão de obra trabalhadora nos centros urbanos, como condição para viabilizar o processo de industrialização, repercute no agravamento da questão habitacional. No governo Vargas, a intervenção partiu da responsabilização do Estado pela garantia de um espaço habitacional para os trabalhadores da cidade, nesse sentido, o valor do bem imóvel se apresenta compatível com os salários da classe trabalhadora. Essa medida, contudo, resulta de um intenso consenso com a elite brasileira. O projeto nacional-desenvolvimentista centralizava-se em dois aspectos principais: primeiro, que a habitação deveria fazer parte da cadeia produtiva, pois geraria desenvolvimento econômico e seria uma grande estratégia de industrialização para o país, e, segundo, que seria vista como formação ideológica, política e moral do trabalhador.

Em resumo, durante quase vinte anos de intensa urbanização e de agravamento do problema da moradia, sucessivos governos revelaram-se incapazes de formular uma proposta para atender ao leque cada vez mais diversificado de necessidades habitacionais do país. A trajetória da Fundação da Casa Popular e, de maneira geral, a produção estatal de moradias, mostram que, no Brasil, a questão nunca esteve no centro das preocupações dos governos populistas (BONDUKI, 2011, p. 125).

Identifica-se como um segundo momento significativo de intervenção estatal na questão habitacional os anos da administração do regime militar, por intermédio da criação do Sistema Financeiro da Habitação e do Banco Nacional da Habitação (BNH). O denso investimento em construções de novas unidades habitacionais foi financiado basicamente pelo Fundo de Garantia por Tempo de Serviço (FGTS). De uma forma geral, pode-se dizer que a classe média foi a maior beneficiada pelos subsídios contidos nesse sistema de financiamento habitacional. Além de atingir mais amplamente as camadas de renda média da sociedade, o BNH teve como característica a construção de loteamentos em zonas distantes das áreas urbanizadas, a exemplo da comunidade carioca Cidade de Deus2.

\footnotetext{
2 No Rio de Janeiro, na década de 1960, o Governador Carlos Lacerda deu início a uma política de remoção das favelas situadas na zona sul da Cidade, construindo um conjunto habitacional na baixada de Jacarepaguá. O surgimento da Cidade de Deus é um caso típico de remoção massiva de famílias de baixa renda para áreas distantes das regiões urbanizadas e, portanto, distantes das possibilidades de trabalho, transporte e serviços.
} 
O período que segue a abertura democrática do país foi marcado pela crise econômica, e, como resposta à crise, apresentou-se um conjunto de ações que, via de regra, impactaram no esvaziamento do financiamento das políticas sociais, entre elas, a habitacional. A matriz de pensamento urbano modernista, a qual orientou o crescimento das cidades dos países centrais do capitalismo, passou a sofrer com o desmonte das propostas oriundas do paradigma neoliberal que acompanharam a reestruturação produtiva no final do século XX. No Brasil, esse modelo foi adotado exclusivamente na chamada cidade formal ou legal, deixando o processo de modernização das cidades brasileiras pela metade. Esse processo de intervenção parcial serviu para ocultar a cidade real e para a formação de um mercado imobiliário restrito e especulativo.

A Caixa Econômica se assume como sucessora do então extinto BNH, entre os anos de 1987 até 1998. Na gestão do Presidente Itamar Franco, foi criado o Programa Habitar (1994), programa que contemplava o trabalho social nas intervenções habitacionais como contrapartida dos estados e municípios. Em 1999, ao fim da primeira gestão do Presidente Fernando Henrique Cardoso, o governo federal passou a sofrer influência do Programa Habitar Brasil - BID (Banco Interamericano de Desenvolvimento). Dessa forma, o Estado brasileiro passou a recorrer aos empréstimos externos para a implementação de políticas urbanas, sobretudo a habitacional. Ao realizar empréstimos, o agente financeiro externo também incorpora suas fórmulas de modelo de gestão de políticas, em total consonância com os fluxos da economia capitalista.

Pode-se dizer que a forma de difusão desse modelo de gestão é frequentemente identificada pelo discurso de atendimento à pobreza, como verniz do processo de subalternização das políticas sócias às econômicas. A incorporação do debate sobre a pobreza na agenda das agências multilaterais é parte do processo de ajustes estruturais de orientação neoliberal, que tem por princípio a reorientação do papel dos Estados nacionais na formulação das políticas sociais. De acordo com essas orientações, sintetizadas nos documentos oficiais formulados pelos consultores do agente financeiro, o Estado passa simultaneamente a enxugar os gastos públicos voltados à política social e a focalizar o atendimento dessas políticas tão somente nos segmentos mais vulneráveis.

Contudo, conforme já mencionado, é nesse mesmo período de crise que se identifica o destaque no debate na sociedade civil acerca da questão urbana. O processo de 
redemocratização da política brasileira proporcionou a confluência de diversas forças, como os movimentos sociais que lutam por moradia, regularização fundiária e políticas sociais públicas. A Constituição Federal de 1988 fortaleceu o poder local e descentralizou a competência sobre a Política de Desenvolvimento Urbano. A incorporação constitucional da questão urbana permitiu a inclusão nas constituições estaduais e nas leis orgânicas municipais de propostas democráticas sobre a função social da propriedade e da cidade.

O direito à moradia esteve subentendido na Constituição Federal brasileira no artigo 182, que estabelece como atribuição do município "ordenar o pleno desenvolvimento das funções sociais da cidade e garantir o bem-estar de seus habitantes" (BRASIL, 1988). A inclusão desse direito inscrito de forma expressa é recente na história urbana do país, datado de 14 de fevereiro de 2000, por meio da emenda constitucional número 26, que, ao alterar a redação do artigo 6으, incluiu a moradia como um direito social fundamental na Carta Magna brasileira.

No ano de 2004, o Ministério das Cidades aprova a Política Nacional de Habitação (BRASIL, 2004), com o objetivo de garantir as condições de moradia com qualidade para todas as camadas da população, especialmente para os que possuem renda baixa. Em 2006, cria-se o Plano Diretor de cada cidade, que, conforme documento do Ministério das Cidades, estabelece os mecanismos para viabilizar o acesso à terra para a produção de moradia, a partir de documentos urbanísticos, quais sejam: Zonas Especiais de Interesse Social (ZEIS); Parcelamento, Edificação e Utilização; Compulsórios - PEUC IPTU Progressivo no Tempo; Desapropriação com Títulos da Dívida Pública; Consórcio Imobiliário.

No ano de 2007, o Governo Federal lança o Programa de Aceleração do Crescimento (PAC), assumindo como meta a promoção de aquecimento no mercado interno a partir de investimento em grandes obras estruturais. Ressalta-se nesse caso a ênfase no apoio às grandes construtoras e empreiteiras do país. No ano de 2008, o Governo Federal cria o Programa Minha Casa Minha Vida (MCMV), voltado ao atendimento do deficit habitacional, com objetivo de abranger famílias com renda de zero a dez salários mínimos. O programa, a partir do ano de 2009, foi responsável por alavancar exponencialmente os índices de investimento em habitação no país. Comparado aos anos iniciais do PAC, os valores investidos se multiplicaram por dez, atingindo uma escala quantitativa histórica na política 
habitacional brasileira. Segundo os dados do Ministério das Cidades, em 2014 os números atingiram aproximadamente 1,8 milhões de novas unidades habitacionais.

Trata-se de um Programa que busca claramente impactar a economia mediante os efeitos multiplicadores gerados pela indústria da construção civil. Além disso, o MCMV aumentou o volume de crédito para a aquisição e a produção de novas habitações, ao mesmo tempo em que reduziu as taxas de juros para ampliar o acesso ao sistema financeiro (CARDOSO, 2013). Sendo assim, essa forma de atendimento serviu de alicerce para o mercado imobiliário e para o aquecimento da economia interna, haja vista os reflexos da crise capitalista deflagrada mundialmente a partir do ano de 2008.

Como prerrogativa do programa, ocorreu a possibilidade de oportunizar aos municípios o desenvolvimento de empreendimentos habitacionais para sanar o deficit, uma vez que, para o ente municipal, o investimento se resume apenas à disponibilização de áreas para a construção das unidades habitacionais, conforme descreve Rolnik (2010, p. 22):

\begin{abstract}
O Programa Minha Casa Minha Vida tem como finalidade criar mecanismos de incentivo à produção e compra de novas unidades habitacionais pelas famílias com renda mensal de até 10 salários mínimos, que residam em qualquer município brasileiro. Para que o Programa Minha Casa Minha Vida construa moradias adequadas e bem localizadas é essencial a participação ativa dos municípios mobilizando instrumentos em seus Planos Diretores que favoreçam a disponibilidade de bons terrenos para o programa, especialmente para famílias com renda de 0 a 6 salários mínimos. Este Programa tem como meta construir um milhão de habitações.
\end{abstract}

A análise da abrangência do programa em termos quantitativos assume relevância histórica no cenário da política habitacional brasileira, contudo, no que se refere ao avanço em escala qualitativa, observa-se que muito ainda há que se trilhar. As críticas ao atual programa do Governo Federal se referem à inadequação da localização dos empreendimentos, construídos, de uma forma geral, fora do tecido urbano, especialmente nas cidades de grande porte. Essa situação reporta às debilidades do extinto sistema do $\mathrm{BNH}$, o mais relevante investimento na área até o PMCMV. Dessa forma, muitos dos conjuntos habitacionais entregues pelo programa promoveram o acesso à habitação em detrimento do não acesso aos bens e aos serviços da cidade. Outra crítica recorrente versa sobre a baixa qualidade arquitetônica e construtiva dos empreendimentos, todos nos 
mesmos moldes (tamanhos e tipificações), que não levam em consideração a diversidade da composição familiar.

Ademais, considera-se preocupante a destinação de recursos públicos à iniciativa privada, deslocando para o mercado a gestão das ações da política habitacional. A viabilidade de novos empreendimentos depende da disponibilidade e do interesse das empreiteiras, dessa forma, a política habitacional se torna refém do jogo comercial, que coloca em segundo plano os empreendimentos voltados à população com renda de até três salários mínimos, em razão da menor margem de lucro sobre esses empreendimentos.

Desde a formulação até a execução do programa, percebe-se a necessidade de revisão de seus aspectos centrais, tal como a desarticulação do programa com a política urbana, bem como a ausência de instrumentos para o enfrentamento da questão fundiária. A operacionalização da política por meio do programa visa predominantemente à construção de novas moradias. Dessa forma, ao não focar em ações de regularização fundiária e de legitimação das ocupações feitas em espaços ociosos no centro da cidade, o programa se exime da discussão acerca da função social da propriedade, reduzindo as possibilidades de realizar o acesso à moradia nos territórios já ocupados pelas famílias atendidas, na perspectiva de garantir a permanência das comunidades em seus locais de origem.

De acordo com a articulação entre os entes federados, a implantação dos empreendimentos habitacionais em áreas bem localizadas depende da participação ativa dos munícipios. Dessa forma, as possibilidades de maior autonomia de as famílias atendidas pelo programa escolherem o seu local de moradia dependem do diálogo estabelecido com os municípios. Ao município, cabe a disponibilização da área, e, como forma de "otimizar" (ainda mais) os recursos públicos, produzindo a um menor custo um maior número de casas, os empreendimentos são predominantemente verticais, e as áreas disponibilizadas, no geral, são aquelas que apresentam menor custo para a aquisição municipal, ou seja, são zonas mais distantes das áreas centrais.

Ao viabilizar reassentamentos a custo ínfimo para os municípios, o programa densifica quantitativamente o acesso à habitação, gerando um quadro de otimismo frente ao enfrentamento do déficit habitacional no país. Em Porto Alegre, a inserção do PMCMV, ao mesmo tempo que trouxe alívio orçamentário para o município e expectativa efetiva de 
redução do déficit habitacional, fez emergir novas situações, reconfigurando a rotina da política e dos seus usuários. Inicialmente, cabe ressaltar que o programa federal, antes de realizar a cobertura das famílias que não estavam cadastradas nos programas municipais preexistentes, passou a socorrer esses programas com dificuldades de conclusão, por razões financeiras. O programa também apresentou facilidades para o encaminhamento de obras diversas do município, em que a remoção de famílias deixou de representar um entrave para a viabilização de projetos urbanísticos, especialmente os viários, priorizados às vésperas do megaevento esportivo Copa do Mundo FIFA.

A implantação do programa na capital gaúcha já apresenta algumas dessas características. Em razão dos altos preços das áreas urbanas centrais, os empreendimentos do PMCMV, para famílias com renda de zero a três salários mínimos, tem se concentrado em locais distantes, por exemplo, a remoção de mais de $80 \%$ das famílias atendidas para o bairro Restinga, localizado no extremo sul do município, $30 \mathrm{~km}$ do centro da cidade. Tais informações foram buscadas junto ao site da Prefeitura Municipal de Porto Alegre, sistematizando-as no quadro 1.

Quadro 1 - Unidades Habitacionais entregues pelo PMCMV em Porto Alegre por localização

\begin{tabular}{|l|l|l|}
\hline PMCMV em Porto Alegre & $\begin{array}{l}\text { Unidades Habitacionais } \\
\text { entregues para famílias de } \\
\text { zero a três salários } \\
\text { mínimos }\end{array}$ & $\begin{array}{l}\text { Bairro do } \\
\text { empreendimento }\end{array}$ \\
\hline 2011 & 492 UH & Restinga \\
\hline 2012 & 916 UH & Restinga \\
\hline 2014 & 360 UH & Partenon \\
\hline 2015 & 180 UH & Partenon \\
\hline Em construção & 1112 UH & Restinga \\
\hline
\end{tabular}

Fonte: elaborado pelos autores.

Ainda sobre o cenário do munícipio de Porto Alegre, ressalta-se que as famílias atendidas não são oriundas do bairro em questão. De uma forma geral, são comunidades que ocupam locais que passaram por obras viárias realizadas pelo município, ou seja, tratase de assentamento involuntário promovido para a viabilização de duplicação de avenidas, ampliação da pista do aeroporto, construção de estacionamentos, entre outros. 
Diante desse cenário, é possível imaginar que o risco de haver repetição da experiência vivenciada nos tempos do BNH é latente. A superação das incompletas formas de mediação da questão habitacional e da segregação sócio espacial não aparecem como objetivo do programa. O foco na construção de novas unidades habitacionais, a questão da localização dos empreendimentos, a qualidade construtiva e o atendimento prioritário à faixa de renda de maior concentração do déficit habitacional, na prática, não assumiram centralidade na execução da política. Dessa forma, permanecem intactas as relações de especulação imobiliária e de apropriação privada do solo, em detrimento da sua função social.

A questão da moradia no capitalismo integra as diferentes formas de enfrentamento "temporais e territoriais do próprio capitalismo em relação às suas crises endógenas nos espaços urbanos" (PEREIRA, 2009, p. 377). Nesse sentido, é possível afirmar que as medidas adotadas pelo Estado para equalizar a questão habitacional, ao longo da história do país, abordaram a questão de forma superficial, sem atingir a raiz do problema: a apropriação privada do solo urbano que determina o seu contorno e ratifica as formas de segregação sócio territorial.

\section{Considerações finais}

Defende-se que o real enfrentamento da questão habitacional tem como premissa a ruptura com a lógica patrimonialista, o combate à especulação imobiliária e a defesa da função social da terra. Essa máxima pode ser explicada pelos seguintes dados: segundo o Plano Municipal de Habitação de Interesse Social de Porto Alegre, o deficit habitacional do município é de 38.572 moradias. De acordo com o IBGE/Censo 2010 (IBGE, 2010), a capital gaúcha tem 48.635 imóveis vagos de um total de 574 mil imóveis. Com base nesse dado, identifica-se com clareza que a materialização da atual legislação que versa sobre função social da terra seria suficiente para a superação do deficit habitacional do município de Porto Alegre. Contudo, indiferente a esse contundente dado, o tratamento dispensado à questão habitacional parte da necessidade de construção de novas unidades habitacionais em locais distantes das áreas centrais do município. Mesmo que a cidade possua um número superior de imóveis vagos em relação à necessidade de moradia, a lógica da função social da propriedade não se aplica. Vale ressaltar que essa não é uma realidade exclusiva 
do município de Porto Alegre. Em outras palavras, trata-se de uma disputa histórica da classe trabalhadora que está longe de findar.

E o direito de morar? Confundido em boa parte da literatura especializada com o direito de ser proprietário de uma casa, é objeto de um discurso ideológico cheio, às vezes, de boas intenções e, mais frequentemente, destinado a confundir os espíritos, afastando cada vez mais pra longe uma proposta correta que remedeie a questão. Por enquanto, o que mais se conseguiu foi consagrar o predomínio de uma visão imobiliária da cidade, que impede de enxergá-la como uma totalidade (SANTOS, 2012a, p. 61)

Nesse franco cenário de disputa pela ocupação da cidade, saúda-se o protagonismo dos movimentos sociais vinculados ao direito à moradia. São longas e consistentes as trajetórias desses movimentos - Movimentos dos Trabalhadores Sem-Teto, Movimento Nacional de Luta pela Moradia, entre tantos outros. Esses movimentos deflagram cotidianamente que a questão do déficit habitacional está para além da construção de novas moradias. Como já mencionado, em muitas cidades a equação entre imóveis vazios supera a demanda por habitação. As ocupações desses espaços ociosos, organizadas pelos movimentos, trazem à tona a possibilidade real de atendimento da política habitacional em regiões urbanizadas e centrais, próximas aos recursos necessários para a realização do direito à cidade.

As possibilidades de materialização da legislação atual dependem da consolidação da "função social" da "propriedade", um paradoxo em si. Constata-se assim que a base da sociedade burguesa é o próprio limite da concretização do direito à moradia. A cultura patrimonialista garante direito ilimitado ao proprietário. O sistema judiciário, via de regra, sobrepõe o direito à propriedade privada às tentativas de validação da função social do espaço e, frequentemente, enquadra como ilegítimas e/ou ameaçadoras à ordem as tentativas da sociedade civil em defender a vida e os direitos humanos fundamentais previstos constitucionalmente.

É relevante ressaltar que a conquista pela atual legislação é fruto de um cenário de intensas e significativas disputas, uma vez que ela representa uma proposta de enfrentamento de ordem estrutural. Materializá-la é o desafio. Apesar do inconteste avanço proporcionado pela criação de uma regulamentação da questão urbana, o instrumento legal por si só não é suficiente para alavancar a reforma urbana preconizada pelos movimentos sociais. A participação popular efetiva nos fóruns que discutem a 
questão urbana ainda está em processo de consolidação. Os avanços quantitativos, ainda que significativos, reforçam a ideia de cidadania condicionada à lógica do mercado, que reduz o cidadão a consumidor.

Dessa forma, no que se refere à atual conformação da política habitacional no Brasil, o repasse de parte do custo para as famílias atendidas por meio de financiamentos subsidiados pelo governo reproduz a lógica de financeirização imobiliária. Esse limite tênue (ou ausência de limite) entre mercado e política pública tem garantido a satisfação de prefeitos e empreiteiras, especialmente nas remoções ocorridas nos últimos anos, ditas necessárias para sediar os megaeventos ou ainda para a garantia da esterilização dos centros urbanos, necessária aos interesses comerciais.

$\mathrm{O}$ atual contexto da política habitacional, centralizada pelo PMCMV, reforça a prioridade na esfera privada e na mercadorização das políticas sociais, uma vez que são as construtoras/empreiteiras as beneficiárias diretas dos recursos de financiamento do programa, na medida em que o destinatário da política é o consumidor, nesse caso específico, o devedor, que deverá assumir a responsabilidade de um financiamento, levando o programa a ser conhecido como "Minha Casa Minha Dívida".

Desse modo, os impressionantes números apresentados pelo Ministério das Cidades, o estímulo à construção civil (que resultou no crescimento econômico e refletiu na criação de inúmeros postos de trabalho) e o investimento pesado (histórico) na construção de milhares de unidades habitacionais são motivos de celebração, ainda que não se possa perder de vista que o programa não representa nenhuma ameaça ao dilema que está na raiz da segregação sócio-territorial: a questão fundiária. Permanece o desafio de uma política habitacional que se efetive em sua plenitude, privilegiando a concepção do valor de uso da moradia, voltada ao atendimento das necessidades e dos direitos da população.

A trajetória das políticas sociais públicas na área da habitação demonstra que a não superação da lógica mercadológica condiciona qualquer intervenção na área ao fracasso. Em 2015, a Caixa Econômica Federal deu início ao processo de reintegração de posse das unidades habitacionais daqueles considerados inadimplentes ao financiamento ${ }^{3}$. Ora, se o programa se propôs a atender uma faixa de "0 a 3" salários mínimos, deveria prever a

\footnotetext{
3 Dados apresentados em reportagem do dia 20 de setembro de 2015 no Diário Gaúcho de Porto Alegre (INADIMPLENTES..., 2015).
} 
inadimplência daqueles que não possuem renda. Nesses casos, contraditoriamente, a política habitacional será ela própria a geradora de déficit. Esses são alguns dos desdobramentos possíveis de uma política social pública que tem como agente central uma instituição financeira.

Entende-se que a política habitacional tem papel central na materialização dos compromissos previstos constitucionalmente, ao contrário de reforçar os interesses mercadológicos da cidade. Os interesses que promovem a privatização dos espaços públicos já são sólidos e suficientemente fortes às formas de resistência apresentadas pela luta dos movimentos sociais urbanos. A expulsão dos territórios e a opção por alternativas de moradia inadequadas é uma forma de a política assumir seu posicionamento contrário à classe trabalhadora, e, com isso, ao não enfrentar as questões que compõem a raiz do problema habitacional no país, a própria política promoverá o agravamento da segregação socioespacial, sem que o mercado precise sujar as mãos.

Também no ano de 2015, o Observatório das Metrópoles divulgou a avaliação do PMCMV em seis estados do país, o material já traz no título a tônica das críticas voltadas ao programa: "Minha casa...e a cidade?" 4 . O estudo aponta para os diminutos reflexos do programa na superação das principais pautas sobre o direito à cidade. O Programa, até o presente momento, apresenta-se como uma intervenção refratária à questão fundiária do país. Dissociado do debate acerca do direito à cidade, indiferente à diversidade da composição familiar, pouco flexível às realidades locais e, especialmente, reprodutor do modelo privatista do acesso financeirizado à moradia. Assumir essas debilidades permite aprimorar as próximas etapas do programa, com vistas a superar a tendência à repetição das antigas e ineficientes tentativas de solucionar o deficit habitacional brasileiro.

\section{Referências}

ARAÚJO, M. S. C. Os donos da casa: das políticas habitacionais aos significados da casa. 2005. 168f. Dissertação (Mestrado de Políticas Públicas e Sociedade) - Universidade Estadual do Ceará, Fortaleza, 2005.

BACHELARD, G. A poética do espaço. São Paulo: Martins Fontes, 2000.

BONDUKI, N. Origens da habitação social no Brasil: arquitetura moderna, lei do inquilinato e difusão da casa própria. 6. ed. São Paulo: Estação Liberdade, 2011.

\footnotetext{
${ }^{4}$ Material disponível em: Livro... (2015).
} 
BRASIL. Presidência da República. Constituição da República Federativa do Brasil de 1988. 5 out. 1988. Disponível em:

<http://www.planalto.gov.br/ccivil_03/Constituicao/Constituicao.htm>. Acesso em: 16 nov. 2015.

. Lei no 10257, de 10 de julho de 2001. Estatuto da cidade. Regulamenta os arts. 182 e 183 da Constituição Federal, estabelece diretrizes gerais da política urbana e dá outras providências. Brasília: Câmara dos Deputados, 2001.

. Ministério das Cidades. Política Nacional de Habitação. Brasília: Ministério das Cidades, 2004. (Cadernos Ministério Cidades Habitação, n. 4).

Ministério das Cidades. Construindo uma política nacional de desenvolvimento urbano. Resoluções da 1a e $2^{\text {a }}$ Conferência Nacional das Cidades. Brasília: Secretaria Executiva do Conselho das Cidades, 2006.

CARDOSO, A. L. O programa minha casa minha vida e seus efeitos territoriais. Rio de Janeiro: Letra Capital, 2013.

IASI, M. L. A Rebelião, a cidade e a consciência. In: MARICATO, E. et al. Cidades rebeldes: passe livre e as manifestações que tomaram as ruas no Brasil. São Paulo: Boitempo, 2013. p. 41-46.

IBGE - INSTITUTO BRASILEIRO DE GEOGRAFIA E ESTATÍ́STICA. Censo demográfico 2010: famílias e domicílios: resultados da amostra. 2010. Disponível em:

<http://www.ibge.gov.br/home/estatistica/populacao/censo2010/familias_e_domicilios/ default_familias_e_domicilios.shtm>. Acesso em: 20 mar. 2015.

INADIMPLENTES terão imóveis do Minha Casa Minha Vida retomados pela Caixa. Diário Gaúcho, Porto Alegre, 20 set. 2015. Disponível em:

<http://diariogaucho.clicrbs.com.br/rs/ dia-a-dia/noticia/2015/09/inadimplentes-teraoimoveis-do-minha-casa-minha-vida-retomados-pela-caixa-4852060.html>. Acesso em: 12 set. 2015.

KOGA, D. Medidas de cidades: entre territórios de vida e territórios vividos. 2. ed. São Paulo: Cortez, 2011.

LIVRO “Minha Casa... E a Cidade?”. Observatório das Metrópoles. Disponível em: <http://www.observatoriodasmetropoles.net/index.php?option=com_k2\&view=item\&id $=1203 \% 3$ Alivro-\%E2\%80\%9Cminha-casa-e-a-cidade\%3F\%E2\%80\%9D\&Itemid=167>. Acesso em: 23 jul. 2015.

LOJKINE, J. O Estado Capitalista e a Questão Urbana. São Paulo: Martins Fontes, 1997.

MARICATO, E. Habitação e cidade. São Paulo: Atual, 1997.

MARX, K. Manuscritos econômico-filosóficos. São Paulo: Boitempo, 2012.

; ENGELS, F. Manifesto do Partido Comunista. Porto Alegre: L\&PM, 2001. 
MOREIRA, R. O espaço e o contraespaço: as dimensões territoriais da sociedade civil e do Estado, do privado e do público na ordem espacial burguesa. In: SANTOS, M.; BECKER, B. K. Territórios, territórios: ensaios sobre o ordenamento territorial. Rio de Janeiro: Lamparina, 2011.

PEREIRA, P. A. P. Política social temas \& questões. 2. ed. São Paulo: Cortez, 2009.

PINTO, M. B. Questão Habitacional como expressão da questão social na sociedade brasileira. Revista Libertas, Juiz de Fora, v. 4-5, p. 92-117, jan./dez. 2005. Disponível em: <http://www.ufjf.br/nugea/files/2010/09/Artigo-Marina.pdf>. Acesso em: 13 set. 2015.

ROLNIK, R. (Org.). Como produzir moradia bem localizada com os recursos do programa minha casa minha vida?: implementando os instrumentos do estatuto das cidades. Brasília: Ministério das Cidades, 2010. Disponível em: <http://polis.org.br/wpcontent/uploads/como_produzir_moradia.pdf>. Acesso em: 20 abr. 2015.

SANTOS, M. Por uma outra globalização: do pensamento único à consciência universal. 6 . ed. Rio de Janeiro: Record, 2001.

. O Espaço do Cidadão. São Paulo: Editora da Universidade de São Paulo, 2012a. . A natureza do espaço. São Paulo: Editora da Universidade de São Paulo, 2012b.

SILVA, M. O. S. Política Habitacional Brasileira: verso e reverso. São Paulo. Cortez, 1989.

UZZO, K.; SAULE JUNIOR, N. J. A trajetória da reforma urbana no Brasil. 2009. Disponível em: <http://base.d-p-h.info/pt/fiches/dph/fiche-dph-8583.html>. Acesso em: 8 abr. 2015. 